\title{
Esophageal Foreign Bodies: Report of Three Unusual Cases with Interesting Scenario
}

\author{
${ }^{1}$ Nikhil Arora, ${ }^{2}$ Kirti Jain, ${ }^{3} \mathrm{JC}$ Passey, ${ }^{4}$ Vikas Malhotra, ${ }^{5}$ Shilpi Dabas
}

\begin{abstract}
We are reporting three cases of unusual foreign bodies of the esophagus along with the unusual scenario in which they were ingested. The objective of the case report is to add to the list of foreign bodies in the previous literature with increasing awareness of otolaryngologists about them and emphasizing the role of rigid endoscopy for safe removal of foreign bodies from the esophagus.
\end{abstract}

Keywords: Deglutition, Deglutition disorder, Esophagus, Foreign body, Rigid endoscopy.

How to cite this article: Arora N, Jain K, Passey JC, Malhotra V, Dabas S. Esophageal Foreign Bodies: Report of Three Unusual Cases with Interesting Scenario. Int J Otorhinolaryngol Clin 2014;6(3):106-108.

Source of support: Nil

Conflict of interest: None

\section{INTRODUCTION}

It is not new to have patients with foreign body ingestion in otolaryngology practice but curiosity is there because of wide variability of objects in the environment and the manner in which these presentations are seen. Ingestion of foreign bodies can be accidental or deliberate and is usually seen at the extremes of life. Children less than 5 years of age are particularly vulnerable followed by the adults with alcohol inebriation and elderly with reduced tactile sensation due to the use of dentures. ${ }^{1}$ Outcome of foreign body ingestion is usually uneventful in case of early diagnosis and prompt removal. We present an account of three unusual foreign bodies, the settings in which these were accidentally ingested, which is particularly unusual and their subsequent successful removal.

\section{CASE REPORTS}

\section{Case 1}

A 24-year-old prisoner was brought to the emergency department with history of accidental ingestion of a

\footnotetext{
${ }^{1,5}$ Postgraduate, ${ }^{2}$ Senior Resident, ${ }^{3}$ Director and Professor ${ }^{4}$ Professor

${ }^{1-5}$ Department of ENT, Maulana Azad Medical College New Delhi, India

Corresponding Author: Nikhil Arora, Postgraduate, Department of ENT, Maulana Azad Medical College, New Delhi, India Phone: 22723737, e-mail: for nikhilarora@yahoo.com
}

polythene pouch full of tobacco leaves. Patient was a habitual tobacco chewer and in order to evade police, he thought of keeping the polythene pouch of tobacco leaves in his mouth to take it along with him to the prison. While on the way, the pouch accidentally slipped and got stuck up in the food passage. Following this patient complained excessive drooling of saliva and difficulty in deglutition to solids as well as liquids. The X-ray showed globular widening of esophagus at level of T2 to T3 vertebrae (Fig. 1A). The patient was taken under general anesthesia and it was found that the pouch containing the tobacco leaves was located $20 \mathrm{~cm}$ from the upper incisors which was removed (Fig. 1B). Patient stayed well and was discharged on the second postoperative day.
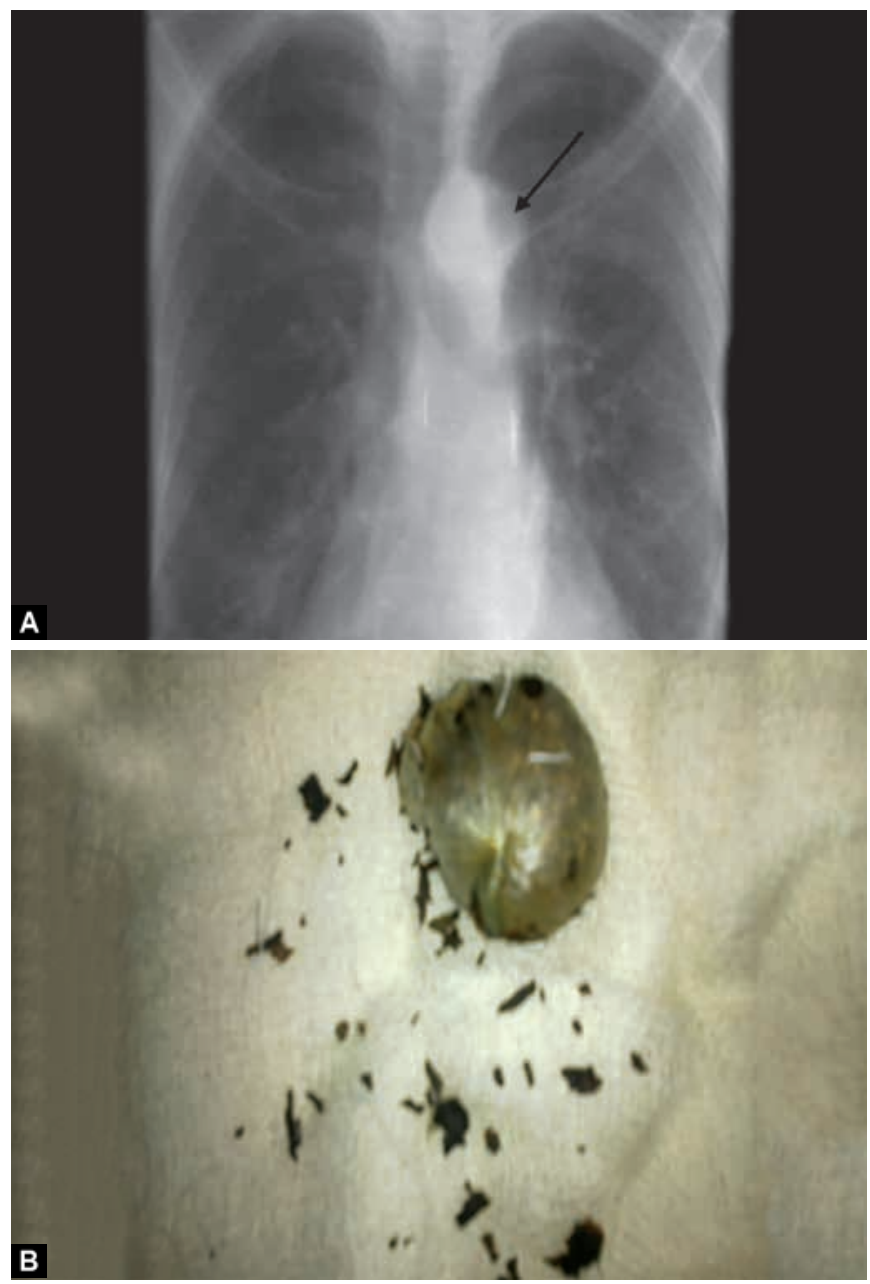

Figs $1 \mathrm{~A}$ and $\mathrm{B}$ : (A) Chest $\mathrm{X}$-ray showing globular widening of esophagus at level of T2 to T3 vertebrae and (B) the pouch containing the tobacco leaves removed with rigid endoscope 


\section{Case 2}

A 5-year-old female child presented with accidental ingestion of some metallic tool. According to the parents while playing the child must have kept the same in the mouth when it got accidentally ingested and stucked up in the food pipe. X-ray was done showed the foreign body at the level of C-7 vertebra. Its removal was attempted under general anesthesia with rigid esophagoscope. However, we had to face real difficulty while attempting its removal as it was a circular tool that had tendency to open up so we had to maintain the circular shape for easy removal throughout the procedure, which was anything but easy (Figs 2A and B). The foreign body was removed without any complication and the child was discharged next day.

\section{Case 3}

A 26-year-old male presented to ENT emergency with complain of accidental ingestion of beer bottle cap while trying to open it by mouth. X-ray was done showed the cap at $\mathrm{T} 1$ vertebra (Fig. 3A). Its removal was attempted under general anesthesia. During removal as the serrated margins of the cap was causing indentation of the posterior esophageal wall, so we used a grasping forceps which gets open on its both arms (Fig. 3B) and one arm of it helped to push the posterior wall away from the serration and other to grasp the anterior surface of cap. That made easy nontraumatic removal of foreign body possible. No postoperative complications were seen and patient discharged next day.

\section{DISCUSSION}

The most common types of ingested objects in the esophagus are food-related foreign bodies, such as bones, meat bolus, nuts and seeds. ${ }^{2}$ Our case series describes nonfood related foreign bodies. Over $90 \%$ of the ingested foreign bodies pass uneventfully through the gastrointestinal tract. ${ }^{3}$ Endoscopic treatment or
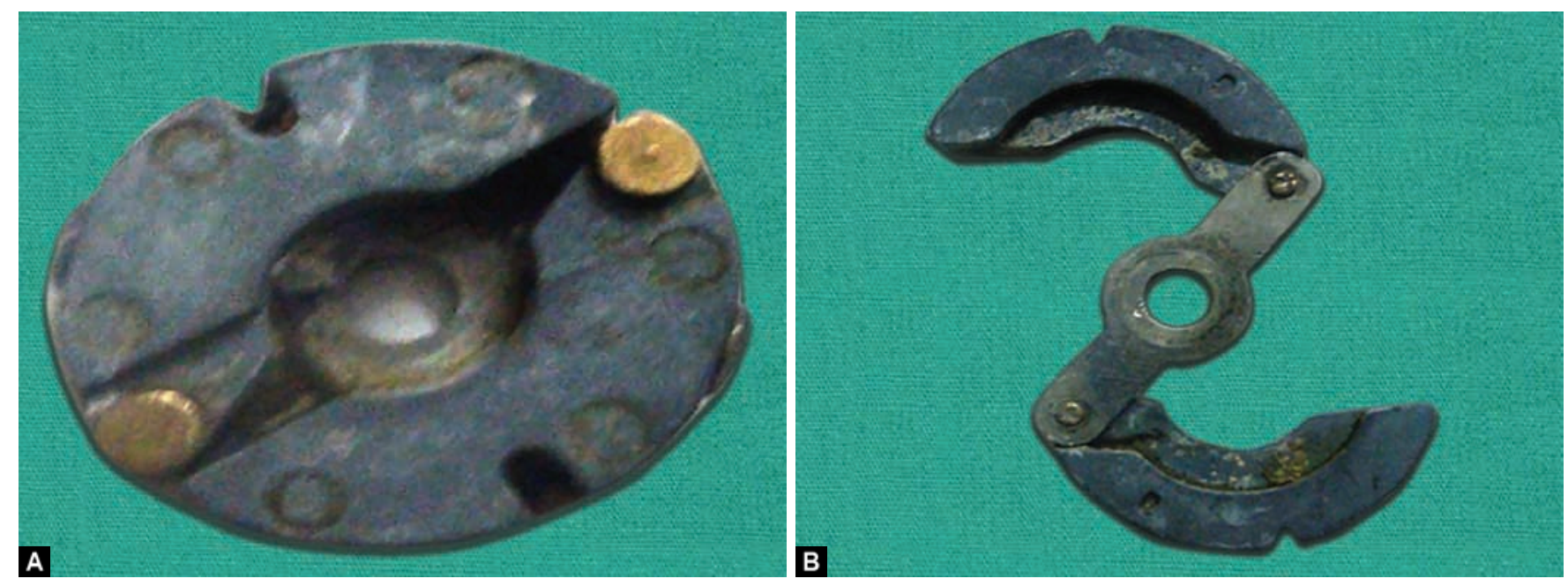

Figs $2 \mathrm{~A}$ and B: Circular toy (foreign body removed) and (B) circular toy that gets opened up during successful removal with rigid endoscope
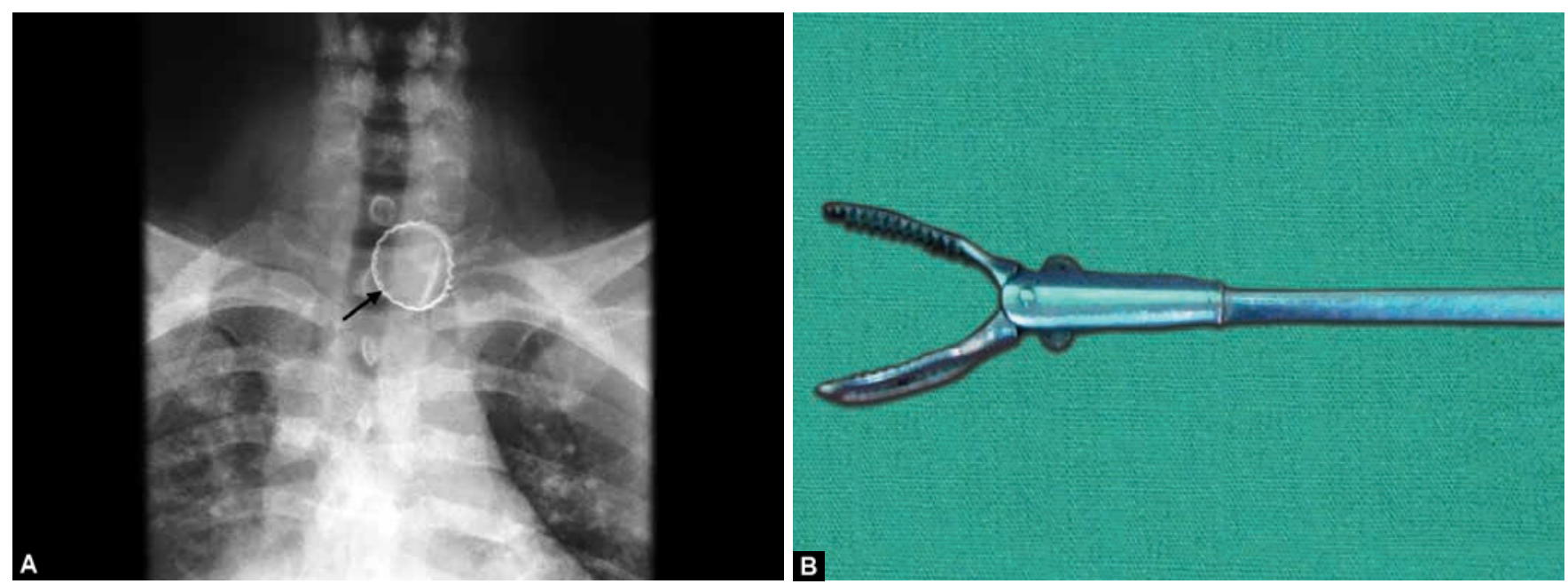

Figs 3A and B: (A) Chest X-ray showing the beer bottle cap at T1 vertebra and (B) grasping forceps that was used to remove the cap during rigid endoscope 
surgical interventions are necessary in 20 and $1 \%$ of cases, respectively. ${ }^{4}$ Intervention is required only when they become impacted in tonsils, base of tongue or lower down. The foreign bodies usually get stuck-up at one of the three esophageal anatomical constrictions: the cricopharyngeal ring, the aortic arch narrowing or the esophagus-gastric junction. ${ }^{5}$ The position of foreign body in the esophagus also differs with age, as in children, the foreign body usually gets impacted in the upper esophagus at the level of the cricopharyngeus muscle as seen in our second case and in adults the foreign body is usually impacted in the lower third of the esophagus as in our first and third case. Patient commonly presents with drooling of saliva, difficulty in deglutition and odynophagia, depending on the location of foreign body. Patients can also present with respiratory symptoms if there is direct pressure on the trachea or secondary esophageal dilatation causing obstructive symptoms. ${ }^{6}$ It is very important to differentiate between the foreign bodies impacted in esophagus in which the patient presents with odynophagia, dysphagia as principal complaints, whereas a foreign body impacted in the respiratory tract will lead to complaints of breathlessness, cough and stridor sometimes, and hence warrants an immediate removal. Foreign bodies in the esophagus (especially penetrating and sharp one) should be removed as soon as possible in view of risk of perforation and related complication, such as mediastinitis, lung abscess, peritonitis, etc. ${ }^{7}$ Before considering the removal of foreign body, duration since ingestion should be enquired upon as duration more than 24 hours is usually associated with secondary infections and edema so, chances of causing perforations are high. These patients should be given a course of steroids and antibiotics to avoid complications. Battery ingestion is exception to this which should always be removed as soon as possible as it can cause mucosal injury in as little as 4 hours. $^{8}$ Endoscopy is the preferred method for esophageal foreign body extraction with a reported success rate of $83 \% ., 10$
Flexible endoscopy is a method which can be done on outpatient basis and without general anesthesia, but this is associated with lumen compromise and not suitable when sharp or penetrating foreign bodies are present. Rigid esophagoscopy is required in such cases especially as it allows dilatation of lumen with nontraumatic removal and also allows postremoval inspection of mucosal injury. In our institution, we prefer to use rigid endoscope for removal of foreign body from esophagus. Surgical treatment must be performed in case endoscopic removal failed due to severely impacted foreign body or esophageal perforation and migration of foreign body.

\section{REFERENCES}

1. Kansara AH, Shah HV, Patel MA, Manjunatharao SV. Unusual case of laryngeal foreign body. Ind J Otolaryngol Head Neck Surg 2007;59(1):63-65.

2. Cangir AK, Tug T, Okten I. An unusual foreign body in the esophagus: report of a case. Surg Today 2002;32(6):523-524.

3. Passey JC, Meher R, AgrawalS, Gupta B. Unusual complication of ingestion of a foreign body. J Laryngol Otol 2003 Jul;117(7): 556-567.

4. Al-Qudah A, Daradkeh S, Abu-Khalaf M. Esophageal foreign bodies. Eur J Cardiothorac Surg 1998 May;13(5):494-498.

5. Von Rahden BHA, Feith M, Dittler HJ, Stein HJ. Cervical esophageal perforation with severe mediastinitis due to an impacted dental prosthesis. Dis Esophagus 2002;15(4):340-344.

6. Macpherson RI, Hill JG, Othersen HB, et al. Esophegeal foreign bodies in children: diagnosis, treatment, and complications. AJR 1996 Apr;166(4):919-924.

7. Badoe EA, Archampong EQ, daRocha-Afodu JT. Foreign bodies in the oesophagus in principles and practice of surgery including surgical pathology in the tropics. 3rd ed. Ghana Pub Cop 2000. p. 356-357.

8. Silverberg M, Tillotson R. Esophageal foreign body mistaken for impacted button battery. Pediatric Emerg Care 2006 Apr; 22(4):262-265.

9. Furihata M, Tagaya N, Furihata T, Kubota K. Laparoscopic removal of an intragastric foreign body with endoscopic assistance. Surg Laparosc Endosc Percutan Tech 2004 Aug;14(4): 234-237.

10. Bounds BC. Endoscopic retrieval devices. Tecniques in Gastrointestinal Endoscopy 2006;8:16-21. 